\title{
Evaluation of heavy chisel plow performance in different speeds in terms of some mechanical performance indicators
}

\author{
Arkan Muhammad Amin Siddiq
}

Yahya Younis Mohsin AL-Obaidi

Agriculture Mechanization Dept. College. of Agric. \& Forestry/ Mosul University /Iraq

Email : arkamn@yahoo.com

\begin{abstract}
This study was conducted to evaluate the performance of heavy chisel plow at the end of January during agricultural season (2018) In the area of Baweizah of the district of Talkif / Ninavah province which is located north east of the city of Mosul Which is far (13) $\mathrm{Km}$ about the city center.Soil texture was silty clay by using two levels of factory of level plowing, the first level was add the tubular roller on the chisel plow and the second level was without the tubular roller from the chisel plow . also two levels of depth plow .the first was $(8-10 \mathrm{~cm})$ and the second was $(12-14 \mathrm{~cm})$ and three levels of speed included $(2.4,4.3$ and $7.1) \mathrm{km} / \mathrm{h}$. to study their effect in some mechanical properties, the experience was factorial with three replication. The differences have been tested by Duncan.the important results are in the following: excelled (add the tubular roller) in the following properties (,Volume of soil disturbed,depth achieved,the appearance tillage), while the level (withput roller reducer) excelled in properties (Draft force, specific resistance), while does not appear any moral differences in the following properties (Fuel consumption). At same time excelled the speed $(2.4) \mathrm{km} / \mathrm{h}$ in the following properties (Draft force, specific resistance, Depth actual of plowing), While the speed (7.1) km/h excelled in the following properties (Fuel consumption ,volume of soil disturbed, the appearance tillage). Register The interaction between the first level tillage (add the roller reducer) and the first forward speed (2.4) $\mathrm{km} / \mathrm{h}$ record moral superiority in the following properties (Depth actual of plowing) while the interaction between the first level tillage and the Third forward speed (7.1) $\mathrm{km} / \mathrm{h}$ record moral excelled in the properties (Volume of soil disturbed ,The appearance tillage), while the interaction between the Second level tillage (without the tubular roller) and the first forward speed $(2.4) \mathrm{km} / \mathrm{h}$ moral excelled in the following properties (Draft force, specific resistance), while the interaction between the second level tillage (without the tubular roller) and the third forward speed (7.1) km/h moral excelled in the properties(Fuel consumption)
\end{abstract}

Key words : heavy chisel plow, add the tubular roller to plow, tillage speeds

\section{Received: 2/9/2018 Accepted 21/1/2019}

\section{Introduction}

The use of agricultural mechanization in an integrated manner to perform the agricultural operations has achieved a significant increase in agricultural production in both quantity and quality by applying multi-system tillage processes and performing cleaning and leveling the field which ensures a uniform distribution of water and nutrients. It is preferable to use plows that penetrate and break the soil layer and making a suitable place for the seed without upsetting the contents of the soil and thus reduce the risk of exposure of the soil for erosion of wind and water, it is recommended to use the plow in the demilitarized lands. Increasing the speed of the mechanized unit of the heavy chisel plow requires greater acceleration of the soil during the process of tillage and also because of the high shearing forces at high speed 
and therefore that's requires greater pull capacities. This is consistent with (Saber, 2011). The increase in the speed of the tractor during the process of tillage leads to the optimal utilization of tractor capacity and reduces the time required to complete the tillage, and then reduced the amount of fuel consumed for the unit area and this is consistent with (Jubouri, 2006), adding the roller to the heavy chisel plow led to increase the size of the soil raised and the reason for this is that the tubes of the reducer during the work contributed to the dismantling of dirt blocks and raised and the weight added to the plow (roller) which led to an increase in depth of the plowshares in the soil and the relationship between the size of the soil The increase in the speed of tillage has increased soil impact. This may due to the fact that the area at high speed was greater than in the case of low velocity, thus increasing the size of soil with increasing The forward speed and velocity is one of the compounds involved in the size of the soils. This is consistent with (Saber, 2011) (Kashmula, 2012). The quality of soil resistance increases with increasing frontal speed of tillage and decreases with increased depth. The reason for the increase in soil quality resistance when increasing the front speed is to move the soil blocks and friction with each other and with the plow machinery results in an increase in the drag force requirements to disassemble the soil blocks by the plow the excavator with the increase of the front speed and this corresponds to both (Rajab, 2005), (Naser and others, 2016). adding the roller is good to crack and soften the blocks of the soil to and then prepare a suitable place for the growth of plants as well as reduce the economic costs resulting from those processes, the spiral pipes of the roller is working to crack the blocks of the soil to smaller sizes and smoothing it as a result of vertical pressure exerted by the roller and this process of smoothing increases the breakage of the dirt masses abandoned by the plow reduces the number of these blocks and gives a good appearance for tillage and this is consistent with (AL-Zubaidi, 2004), increasing the speed of practical tillage contributed to reduce the number of soil blocks in the field because the high speed works to increase the speed of hitting the blocks and dumping it at a distance beyond the slow speed, thus dismantling the blocks of the soil will be better and it will reduce its number (Rajab, 2005). The non-leveling depth of the plowing is one of the problems affecting the stability of the process of tillage, Which in turn affect the provision of a good seed place, while the weapon plays an important role in this stability, and the increase in speed reduces the stability of the depth due to the increase of resistance composition by increasing the acceleration. (Plouffe and others, 1999). Due to the importance of knowing the effect of adding the roller to the machine and not adding and the front speed of the tillage and to obtain the best indicators of performance of the unit can be conducted this experiment accomplished in order to find the best combination of them.

\section{Research materials and methods}

The study was conducted in one of the agricultural fields in the area of Baweizah (northeast of Mosul, $13 \mathrm{~km}$ from the center of the city) for the agricultural season (2018) in late January. The field was abandoned and not cultivated for more than three years. by using two tractors with a capacity of (120) hppower When the experiment was performed because the traction force meter was not available from the three clamping points of the hydraulic lifting device in the tractor directly, the main tractor used in the research was the Massey Ferguson 298 four-wheel drive and was 
Brazilian- the front tractor pull the second tractor which the plow was suspended by the three suspension points. The heavy chisel Spanish-produced springy-loaded plow was produced by Kverneland has been used, it has the following specifications: (11) shares, the width of the design work (3) meters, the weight (710) $\mathrm{kg}$, the roller with the weight of (270) $\mathrm{kg}$, the diameter of the roller (40) $\mathrm{cm}$, containing (8) spiral pipes diameter (5) $\mathrm{mm}$. The experiment was designed using Duncan test for two levels of tillage and three levels of speed $(2 \times 3)$ and three replicates, (18) experimental units and the area of the experimental unit was (90) $\mathrm{m}^{2}$ with (30) $\mathrm{m}$ in length and (3) $\mathrm{m}$ in width (Daoud and Elias 1990).

1- Level of tillage (A) at two levels (A1 with roller) (A2 without roller).

2- The forward speed of the tractor $(B)$ is in three levels $(2.4,4.3,7.1) \mathrm{km} / \mathrm{h}$, respectively.

\section{Studied indicators}

\section{1- Draw Power}

Draw power is the result of multiplying draw force by forward speed. Abood (1980) and the required power had been calculated from the following equation, Ezzat and Lutfi (1979):

$\mathrm{Dp}=\mathrm{Ft} * \mathrm{VP} / 270$

Dp: Draw Power (hp)

Ft : Draw Force $(\mathrm{kg})$

VP: practical tillage speed $(\mathrm{km} / \mathrm{h})$

\section{2- Fuel Consumption (L/ha)}

Fuel consumption has been measured by addition method by using a graduated cylinder, the tank should be fully filled then starting the tractor and starting the work, after finishing working-line the tractor should be turn off immediately, then the fuel should be added to the tractor by using the graduated cylinder, the amount of this addition represents the fuel consumption,( AL-Hashem and others ,2000) and as the following equation:

$\mathrm{FC}=\mathrm{Q} \times 10000 / \mathrm{TL} \times \mathrm{Wp} \times 1000$

FC: the amount of fuel consumption per hectare $(\mathrm{L} / \mathrm{ha})$

$\mathrm{Q}$ : the amount of fuel consumption during the process $(\mathrm{ml})$

TL: processing length $(\mathrm{m})$

Wp: tillage actual working width $(\mathrm{m})$

\section{3-Volume of soil disturbed}

Is the volume of the soil raised by the plow during the tillage period, It depends on the practical productivity of the machine and the depth of actual tillage, The volume of the raised soil can be calculated according to the following equation: (Bukhair and others, 1988).

S.V.D $=\mathrm{EFC}^{*} \mathrm{DP}_{\mathrm{P}}^{*} 100$

S.D. $V=$ volume of the raised soil $\left(\mathrm{m}^{3} / \mathrm{h}\right)$

EFc: Actual field productivity (ha/h).

$\mathrm{D}_{\mathrm{P}}$ : Actual tillage depth $(\mathrm{cm})$.

\section{4- Soil specific resistance}

It represents a portion from the whole resistance per tillage area section nd it can be measured as the following equation: (Yaya,1998) 
$\mathrm{SR}=\mathrm{F}_{\mathrm{t}} /\left(\mathrm{W}_{\mathrm{P}} * \mathrm{D}_{\mathrm{P}}\right)$

SR: Specific draw resistance $\left(\mathrm{KN} / \mathrm{m}^{2}\right)$.

Dp: actual tillage depth $(\mathrm{m})$.

Wp: Actual tillage width $(\mathrm{m})$.

Ft: draw required force $(\mathrm{KN})$.

\section{5- Tillage appearance (number of soil blocks with diameters more than 5 or 10 cm)}

It is estimated by using a wooden frame with $1 \mathrm{~m}^{2}$ area, it is placed on a random placed on the plowed land and after 9 locations in each process, then put the frame on the plowed land and calculate only the blocks that their diameter is more than $(5) \mathrm{cm}$ and (10) $\mathrm{cm}$ and neglect the other, the process with the smallest number and size of large blocks is the best, in general the tillage of the tiller is less rough than the rest of the plows and depends on the moisture content of the plowed soil.

\section{6 -Actual Depth}

The depth achieved was calculated by using two rulers $30 \mathrm{~cm}$ long for each ruler, the first ruler was placed vertically in the bottom, and the second was placed horizontally on the surface of the earth as the two rulers intersect at a right angle, noting that the theoretical depth tuned by the plow was $(8-10) \mathrm{cm}$ and the second (1214) $\mathrm{cm}$.

\section{1- Draw Power}

\section{Results and Discussion}

Table (1) shows that the addition of the roller to the machine increased the draw power. The highest value was recorded when adding the roller to the machine reached (21.40) hp compared with the removal of the roller from the machine where the lowest value which was recorded reached (18.93) hp. This is due to the fact that the addition of the roller to the machine leads to increase the required power because of the soil friction with the sliding chairs of the roller and adding the roller to the machine leads to increase the weight, which in turn increases the depth of the tillage and increases the force of the draw and its required power. It was also found that the higher the actual speed the greater the power required for the draw, with the highest value reached (32.29) $\mathrm{hp}$ at the third speed (7.1) $\mathrm{km} / \mathrm{h}$, while the lowest value recorded reached (10.10) hp at the first speed (2.4) $\mathrm{km} / \mathrm{h}$. This is due to the fact that increasing the speed requires greater acceleration of the soil during the process of displacement in tillage as well as because of the high shear strength at high speed and therefore needs greater power. This is consistent with (Sabr, 2011). interaction between the plowing level (adding and removing the roller from the machine) with the front speed has a significant effect on the draw power.

It was found that increasing the front speed of tillage for both levels increased the required drawing power. The maximum value of the drawing power was recorded when adding the roller at the speed $(7.1 \mathrm{~km} / \mathrm{h})$ was $(34.58) \mathrm{hp}$, while by removing it from the machine at speed $(2.4 \mathrm{~km} / \mathrm{h})$ recorded a minimum value of (9.64) hp. 
Table (1) shows the effect of the studied factors studied on the drawing power (hp)

\begin{tabular}{|c|c|c|c|c|}
\hline \multirow{2}{*}{$(\mathrm{A})$} & \multicolumn{3}{|c|}{ Speed km/h (B) } & Tillage level \\
& 7.1 & 4.3 & 2.4 & $(\mathrm{~A})$ \\
\hline $21.40 \mathrm{a}$ & $34.58 \mathrm{a}$ & $19.05 \mathrm{c}$ & $10.57 \mathrm{e}$ & $(\mathrm{A} 1)$ \\
\hline $18.93 \mathrm{~b}$ & $30.01 \mathrm{a}$ & $17.14 \mathrm{~d}$ & $9.64 \mathrm{e}$ & $(\mathrm{A} 2)$ \\
\hline & $32.30 \mathrm{a}$ & $18.09 \mathrm{~B}$ & $10.10 \mathrm{c}$ & (B) \\
\hline
\end{tabular}

\section{2- Fuel Consumption (L/ha)}

Table (2) shows that the addition of the roller to the machine resulted in an increase in fuel consumption. The lowest value was 11.25 liters per hectare when the roller was removed from the machine compared with its addition, the highest value was 11.67 liters per hectare. This may due to the addition of the roller to the machine that will increase the weight of the plow which in turn increases the depth of tillage, leading to increase in the amount of fuel consumed and this is confirmed with (AlTaa'e, 2006). The effect of actual speed on fuel consumption (L / ha) has shown that increasing the front speed of tillage leads to a reduction in fuel consumption, the lowest value was (8.14) liters / ha at the third speed $(7.1) \mathrm{km} / \mathrm{h}$, while the highest value (15.19) liters / ha at the first speed (2.4) $\mathrm{km} \mathrm{/} \mathrm{h}$, This may be due to the inefficient use of tractor capacity when working at a relatively slow speed, resulting in energy loss, at relatively high speeds, this energy is better exploited and it will reduce the time required to complete the tillage of the unit area, these results are consistent with the findings of (Al-Joubury, 2009), for the effect of the interaction between the level of tillage and the actual speed on the amount of fuel consumed ( $1 / \mathrm{ha}$ ), It was found that adding the roller led to increase the amount of fuel consumed and the faster the speed, the less fuel consumption, When the roller was removed from the machine and at the speed of $7.1 \mathrm{~km} / \mathrm{h}$, the lowest fuel consumption recorded was (7.78) 1/ha, while when adding the roller to the machine and at the speed of $(2.4) \mathrm{km} / \mathrm{h}$, the highest value of fuel consumption was (15.33) 1/ha.

Table (2) shows the effect of the studied factors in fuel consumption (L / ha)

\begin{tabular}{|c|c|c|c|c|}
\hline \multirow{2}{*}{$(\mathrm{A})$} & \multicolumn{3}{|c|}{ Speed km/h (B) } & Tillage level \\
& 7.1 & 4.3 & 2.4 & $(\mathrm{~A})$ \\
\hline $11.67 \mathrm{a}$ & $8.50 \mathrm{c}$ & $11.20 \mathrm{~b}$ & $15.33 \mathrm{a}$ & $(\mathrm{A} 1)$ \\
\hline $11.25 \mathrm{a}$ & $7.78 \mathrm{c}$ & $10.96 \mathrm{~b}$ & $15.04 \mathrm{a}$ & $(\mathrm{A} 2)$ \\
\hline & $8.14 \mathrm{C}$ & $11.08 \mathrm{~b}$ & $15.19 \mathrm{a}$ & (B) \\
\cline { 2 - 4 } & &
\end{tabular}

\section{3- Volume of soil disturbed $\left(\mathrm{m}^{3} / \mathrm{h}\right)$}

Table (3) shows that the addition of the roller to the machine affected the volume of the soil disturbed, when adding the roller to the machine the highest recorded value of the volume of the disturbed soil was $(1142.69) \mathrm{m}^{3} / \mathrm{h}$, compared with the result after removing the roller where the lowest value recorded reached (1072.38) $\mathrm{m}^{3} / \mathrm{h}$, The reason for the increase in the volume of soil raised when adding the roller to the machine that the drum of the roller during the work contributed to the dismantling of the soil blocks and raised it and the weight added to the plow (roller) contributed to increase the depth of the weapons of the plow in the soil and the correlation is positive between the volume of the disturbed soil and the depth of tillage, this is consistent 
with the results obtained by (Al-Shujairy and others, 2008). And in the impact of the forward speed of tillage on the volume of the disturbed soil $\mathrm{m} 3 / \mathrm{h}$. It has been shown that the higher the forward speed, the greater the volume of the disturbed soil, the highest value of the volume of soil raised at the third speed (7.1) km / h was (1574.08) $\mathrm{m}^{3} / \mathrm{h}$, While the lowest value of the raised soil volume was $\left(671.19 \mathrm{~m}^{3} / \mathrm{h}\right.$ at the first speed of (2.4) $\mathrm{km} / \mathrm{h}$, This may due to the fact that the plowed area at high velocity was greater than that compared with the low velocity, thus increasing the volume of the raised soil will be with the increase of the forward velocity, the speed is one of the compounds involved in the volume of the raised soil, this consistent with (Sabr, 2011) , (Kashmula, 2012). The effect of the double overlap between the level of tillage (addition of the roller and removing it from the machine) and the actual velocity and their effect on the volume of the raised soil $\mathrm{m}^{2} / \mathrm{h}$. It was found that the higher the actual velocity of both levels of tillage, the greater the volume of the raised soil. The highest recorded value when adding the roller to the machine which reached (1645.29) $\mathrm{m}^{3} / \mathrm{h}$ at speed $(7.1) \mathrm{km} / \mathrm{h}$, compared with the results after removing the roller from the machine and at the speed of (2.4) $\mathrm{km} / \mathrm{h}$ the lowest recorded value reached (659.60) $\mathrm{m}^{3} / \mathrm{h}$.

Table (3) shows the effect of the studied factors on the volume of the disturbed soil $\left(\mathrm{m}^{3} / \mathrm{h}\right)$

\begin{tabular}{|c|c|c|c|c|}
\hline \multirow{2}{*}{$(\mathrm{A})$} & \multicolumn{3}{|c|}{ Speed km/h (B) } & \multirow{2}{*}{$\begin{array}{c}\text { Tillage level } \\
(\mathrm{A})\end{array}$} \\
\cline { 2 - 4 } & 7.1 & 4.3 & 2.4 & $(\mathrm{~A} 1)$ \\
\hline $1142.69 \mathrm{a}$ & $1645.29 \mathrm{a}$ & $1100.01 \mathrm{c}$ & $682.78 \mathrm{e}$ & $(\mathrm{A} 2)$ \\
\hline $1072.38 \mathrm{~b}$ & $1502.87 \mathrm{~b}$ & $1054.66 \mathrm{~d}$ & $659.60 \mathrm{e}$ & $(\mathrm{B})$ \\
\hline
\end{tabular}

\section{4- Soil specific resistance $\left(\mathrm{kg} / \mathrm{cm}^{2}\right)$}

Table (4) shows that the addition of the roller to the machine has increasing soil specific resistance. The hieghest recorded value when adding the roller was (0.395) $\mathrm{kg} / \mathrm{cm}^{2}$ compared with the value when removing the roller from the machine, the lowest value was $(0.374) \mathrm{kg} / \mathrm{cm}^{2}$, this may due to the fact that the addition of the roller has increased the draw power as the draw power is from the compounds of the soil specific resistance, the soil specific resistance increases.

The impact of the forward speed of tillage was observed on the soil specific resistance characteristic. That the higher the actual speed of tillage accompanied by an increase in soil specific resistance, the highest value was $(0.450) \mathrm{kg} / \mathrm{cm}^{2}$ at the third speed $(7.1) \mathrm{km} / \mathrm{h}$, while the lowest value was $(0.333) \mathrm{kg} / \mathrm{cm}^{2}$ at the first speed (2.4) $\mathrm{km} / \mathrm{h}$, the increase in soil quality resistance when increasing front speed is due to the movement of soil blocks and friction with each other and with plow weapons resulting in an increase in the draw force requirements for the dismantling of the soil blocks by plow weapons with increased front speed and this is consistent with (Rejab, 2005) and (Naser and others, 2016). while for the effect of the dual overlap between the plowing level (adding the roller or removing it from the machine) and the actual velocity and their effect on soil specific resistance, It was found that the higher the actual speed of both plowing levels, the greater the soil specific resistance. The highest value was recorded when adding the roller to the machine was $(0.461) \mathrm{kg} / \mathrm{cm}^{2}$ at speed $(7.1)$ 
$\mathrm{km} / \mathrm{h}$, compared with when removing the roller from the machine the minimum recorded value was $(0.325) \mathrm{kg} / \mathrm{cm}^{2}$ at speed $(2.4) \mathrm{km} / \mathrm{hour}$.

Table (4) shows the effect of the studied factors in soil specific resistance $\left(\mathrm{kg} / \mathrm{cm}^{2}\right)$

\begin{tabular}{|c|c|c|c|c|}
\hline \multirow{2}{*}{$(\mathrm{A})$} & \multicolumn{3}{|c|}{ Speed km/h (B) } & Tillage level \\
& 7.1 & 4.3 & 2.4 & $(\mathrm{~A})$ \\
\hline $0.395 \mathrm{a}$ & $0.461 \mathrm{a}$ & $0.382 \mathrm{c}$ & $0.342 \mathrm{~d} \mathrm{e}$ & $(\mathrm{A} 1)$ \\
\hline $0.374 \mathrm{~b}$ & $0.439 \mathrm{~b}$ & $0.358 \mathrm{~d}$ & $0.325 \mathrm{e}$ & $(\mathrm{A} 2)$ \\
\hline & $0.450 \mathrm{~A}$ & $0.370 \mathrm{~b}$ & $0.333 \mathrm{c}$ & (B) \\
\hline
\end{tabular}

\section{5- Tillage appearance (for soil blocks of more than $10 \mathrm{~cm}$ in diameter)}

Table (5) shows that the addition of the roller to the machine led to a reduction in the number of soil blocks of greater than (10) $\mathrm{cm}$ in diameter per the square meter, the lowest recorded value at the first level (after adding the roller) was (3.26) block/ $\mathrm{m}^{2}$ compared to the second level (after removing the roller) which recorded the highest value (14.29) block/ $\mathrm{m}^{2}$, the reduction of the number of the soil blocks of greater than $(10) \mathrm{cm}$ in diameter when adding the roller may be due the fact that the pipes of the spiral roller are working to break down soil blocks, crushing them and softening them to small sizes as a result of the vertical pressure applied by the roller on the soil blocks, this smoothing process further breaks the blocks of the soil abandoned by the plow, reducing the numbers of these blocks and giving a good appearance for tillage and this is consistent with (Al-Zubaidi, 2004). For the effect of increasing the speed on the appearance of tillage, it was noticed that increasing the speed led to a decrease in the number of soil blocks of greater than (10) $\mathrm{cm}$ in diameter. The lowest recorded value was (6.66) block/ $\mathrm{m}^{2}$ at the third speed (7.1) $\mathrm{km} / \mathrm{h}$, while the highest recorded value was (10.11) block $/ \mathrm{m} 2$ at speed of (2.4) $\mathrm{km} / \mathrm{h}$. The decrease in the number of soil blocks of greater than (10) $\mathrm{cm}$ in diameter when increasing the speed may due to that increasing the speed increases the speed of extrusion of soil blocks and hit them with plow weapons which cause its coefficient of disassembly to increase (Dismantling soil blocks further) these results were consistent with (Rajab, 2005), and in the dual overlap between the plowing level (adding the roller to the machine and removing it) and the actual speed of tillage and their impact on the appearance of tillage on the soil surface. It is observed that when increasing the forward speed for the both levels the number of soil blocks of greater than (10) $\mathrm{cm}$ in diameter increases. The lowest recorded value after adding the roller was (1.77) block $/ \mathrm{m}^{2}$ at speed of $(7.1) \mathrm{km} / \mathrm{h}$, compared with that when removing the roller from the machine at speed of (2.4) $\mathrm{km} / \mathrm{h}$ and the highest recorded value was (15.99) block/ $\mathrm{m}^{2}$. 
Table (5) shows the effect of the studied factors in the tillage appearance for soil blocks of more than $(10) \mathrm{cm}$ in diameter

\begin{tabular}{|c|c|c|c|c|}
\hline \multirow{2}{*}{$(\mathrm{A})$} & \multicolumn{3}{|c|}{ Speed km/h (B) } & \multirow{2}{*}{$\begin{array}{c}\text { Tillage level } \\
\text { (A) }\end{array}$} \\
\cline { 2 - 4 } & 7.1 & 4.3 & 2.4 & $(\mathrm{~A} 1)$ \\
\hline $3.26 \mathrm{~b}$ & $1.77 \mathrm{~d}$ & $3.77 \mathrm{c} \mathrm{d}$ & $4.22 \mathrm{c}$ & $(\mathrm{A} 2)$ \\
\hline $14.29 \mathrm{a}$ & $11.55 \mathrm{~b}$ & $15.33 \mathrm{a}$ & $15.99 \mathrm{a}$ & (B) \\
\hline
\end{tabular}

\section{6- Tillage appearance (for soil blocks of more than $5 \mathrm{~cm}$ in diameter)}

Table (6) shows that the addition of the roller to the machine led to a reduction in the number of soil blocks of greater than (5) $\mathrm{cm}$ in diameter per the square meter, the lowest value at the first level (after adding the roller) was (12.70) block $/ \mathrm{m}^{2}$ compared to the second level (after removing the roller), which the highest value was (17.27) block $/ \mathrm{m}^{2}$. And from the impact of increasing the speed on the appearance of the tillage, it was found that increasing the actual speed led to a decrease in the number of soil blocks with a diameter greater than $(5) \mathrm{cm}$, the lowest recorded value was (12.91) block $/ \mathrm{m}^{2}$ at the third speed $(7.1) \mathrm{km} / \mathrm{h}$, while the highest value was (17.30) block $/ \mathrm{m}^{2}$ at speed (2.4) $\mathrm{km} / \mathrm{h}$. while for the effect of dual overlap between the level of tillage and the actual speed of tillage and its impact on the appearance and roughness of the surface of the soil. It was found that when increasing the speed and for both levels led to the reduction of the number of soil blocks of more than $(5) \mathrm{cm}$ in diameter, the lowest recorded value after adding the roller was (11.17) $\mathrm{km} / \mathrm{m}^{2}$ at speed of (7.1) $\mathrm{km} / \mathrm{h}$, compared with when removing the roller at speed of $(2.4) \mathrm{km} / \mathrm{h}$, the highest value was $(20.22) \mathrm{block} / \mathrm{m}^{2}$. for the effective reasons for changing the level of tillage (adding the roller or removing it from the machine) and the speed of tillage they are the same as those mentioned in paragraph (5) themselves.

Table (6) shows the effect of the studied factors in the tillage appearance for soil blocks of more than (5) $\mathrm{cm}$ in diameter

\begin{tabular}{|c|c|c|c|c|}
\hline \multirow{2}{*}{$(\mathrm{A})$} & \multicolumn{3}{|c|}{ Speed km/h (B) } & Tillage level \\
& 7.1 & 4.3 & 2.4 & $(\mathrm{~A})$ \\
\hline $12.70 \mathrm{~b}$ & $11.17 \mathrm{c}$ & $12.55 \mathrm{c}$ & $14.39 \mathrm{~b} \mathrm{c}$ & (A1) \\
\hline $17.27 \mathrm{a}$ & $14.66 \mathrm{~b} \mathrm{c}$ & $16.94 \mathrm{ab}$ & $20.22 \mathrm{a}$ & (A2) \\
\hline & $12.91 \mathrm{~b}$ & $14.75 \mathrm{a} \mathrm{b}$ & $17.30 \mathrm{a}$ & (B) \\
\hline
\end{tabular}

\section{7- Depth achieved (cm)}

Table (7) shows that the addition of the roller to the machine led to an increase in the depth of plowing. The highest value was recorded when adding the roller to the machine was $(11.35) \mathrm{cm}$ compared when removing the roller from the machine the lowest recorded value was $(11.12) \mathrm{cm}$. This may due to the fact that the addition of the roller to the plow led to an increase in the depth of the tillage due to the increased weight gained from the roller on the plow, which led the weapons of the plow to achieve deeper penetration in the soil. From the effect of the front speed on the achieved depth, It was found that the higher the actual speed of the tillage, the lower the depth for both of plowing levels, the highest value at the first speed (2.4) $\mathrm{km} / \mathrm{h}$ was $(11.79) \mathrm{cm}$, while the lowest value at the third speed $(7.1) \mathrm{km} / \mathrm{h}$ was $(10.83) \mathrm{cm}$, this 
is due to the fact that increasing the actual speed of the tillage process leads to reduce the stability of the plow, increasing the speed reduces the stablity of the depth due to increased resistance compounds by increasing the acceleration of the movement given to the soil and this is consistent with (plouffe and others, 1999). while for the effect of the dual overlap between the level of tillage (adding and removing the roller) and the actual speed and their effect on the depth achieved, it was found that increasing the speed with both plowing levels reducing the depth of the achieved plowing. The highest recorded value when adding the roller was $(11.94) \mathrm{cm}$ at speed $(2.4) \mathrm{km} / \mathrm{h}$. while the lowest recorded value when removing the roller wasf rom the machine was $(10.53) \mathrm{cm}$ at speed of $(7.1) \mathrm{km} / \mathrm{h}$.

Table (7) shows the effect of the studied factors on the depth achieved

\begin{tabular}{|c|c|c|c|c|}
\hline \multirow{2}{*}{$(\mathrm{A})$} & \multicolumn{3}{|c|}{ Speed km/h (C) } & \multirow{2}{*}{$\begin{array}{c}\text { Tillage level } \\
(\mathrm{A})\end{array}$} \\
\cline { 2 - 4 } & 7.1 & 4.3 & 2.4 & $(\mathrm{~A} 1)$ \\
\hline $11.53 \mathrm{a}$ & $11.14 \mathrm{c}$ & $11.53 \mathrm{~b}$ & $11.94 \mathrm{a}$ & $(\mathrm{A} 2)$ \\
\hline $11.12 \mathrm{~b}$ & $10.53 \mathrm{~d}$ & $11.22 \mathrm{c}$ & $11.64 \mathrm{~b}$ & $(\mathrm{C})$ \\
\hline
\end{tabular}

\section{Conclusions}

The addition of the roller to the heavy chisel plow showed an increase in the efficiency of the performance, the size of the soil being raised and the depth achieved as well as an decrease in the number of soil blocks in the field. While at the same time led to increase draw power and increasing fuel consumption and specific resistance of the soil.

Increasing plowing speed (2.4-7.1) $\mathrm{km} / \mathrm{h}$ for the mechanical unit led to increase the size of the raised soil, and reducing fuel consumption but in the same time led to increase draw power and the specific resistance of the soil and led to reduce the efficiency of the performance but it contributed in improving tillage appearance of the field.

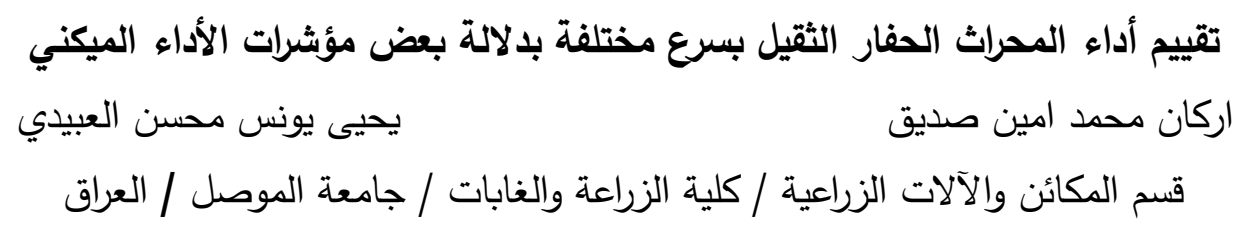

Email : arkamn@yahoo.com

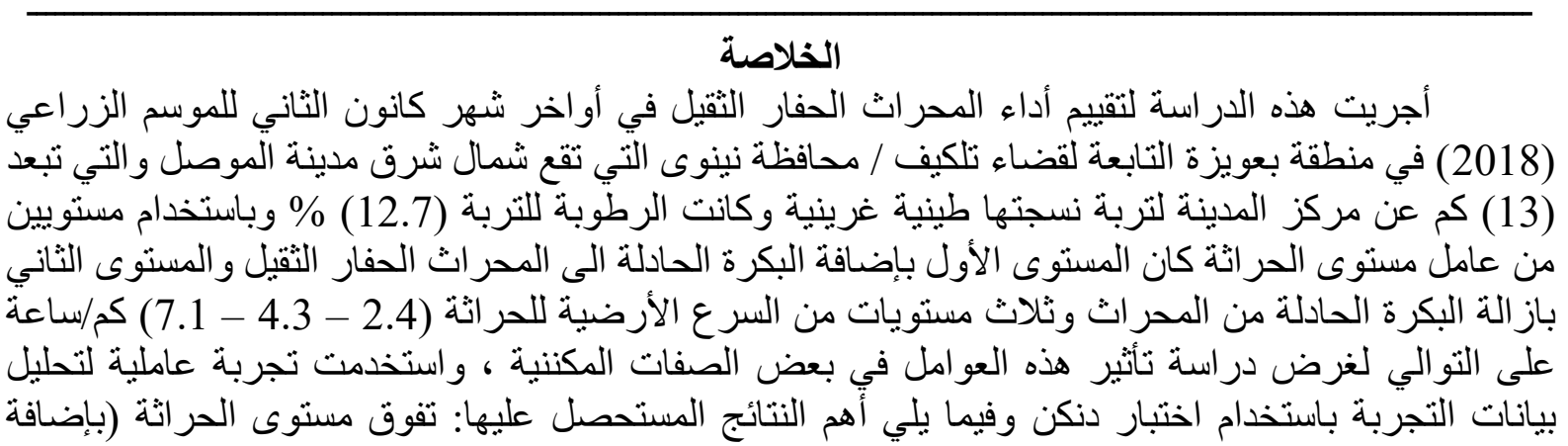


البكرة الحادلة إلى الآلة ) في الصفات : حجم التربة المثار ، و العمق المتحقق ، ومظهر الحراثة للكتل الترابية

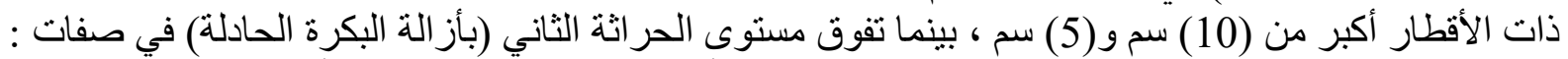

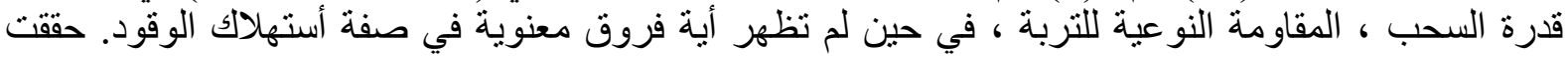

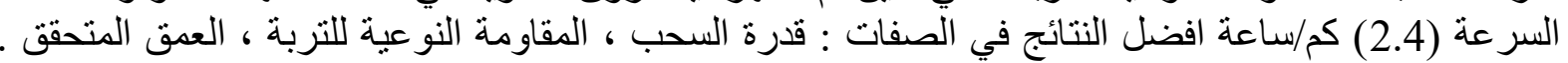

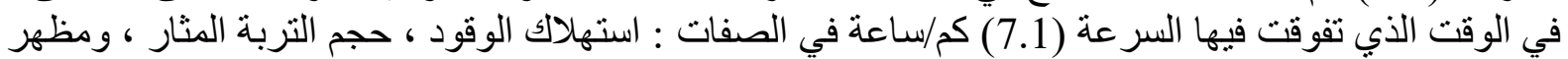

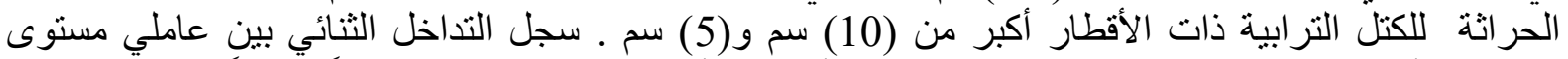

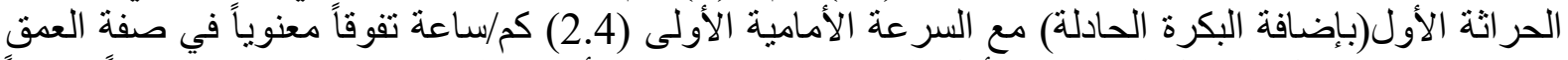

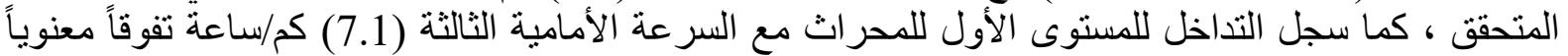

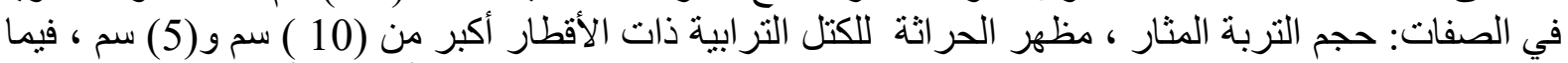

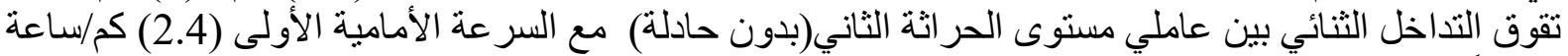

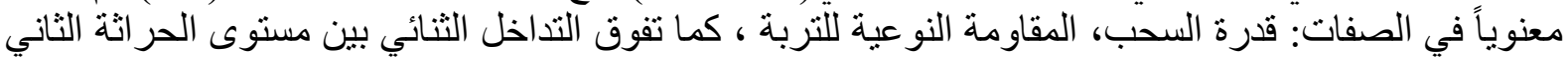

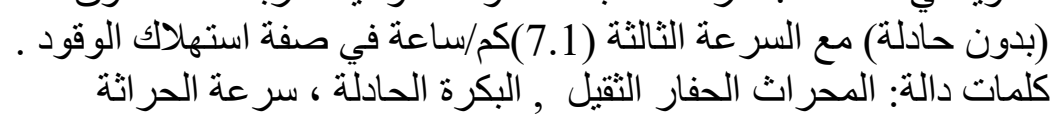

\section{تاريخ تسلم البحث 2018/9/2، وقبوله 2019/1/21}

\section{References}

AL-Hashem , A. H. ; S. K. Abbouda and M. O. Saeed (2000) . The effect of rear wheel tract width and working depth on performance of 2WD tractor . Res. Bult ., No (93), Res. cent. Coll. Of Agri., King saud Univ. , pp (5-21) .

AL-Jubouri, Mossa Abd Shoga (2006) . Effect of forward speed and soil moisture in some performance indicators soil physical properties and sun flower yield, University of Babylon Journal .

AL-Shujairy, Tahseen Alawi Thele' (2008). Effect of added weights of leading tires in tug and type of plow and depth of tillage in some performance indicators of mechanical unit and some physical properties of the soil, Master thesis, Department of Agricultural Mechanization, Faculty of Agriculture, University of Baghdad.

Al-Taa'e, Mahmood Eleaas (2006). Effect of the shape of the drill plow in the requirements of the ability of the power tractor and some physical properties of the soil , , Department of Agricultural Mechanization, Faculty of Agriculture and Forestry, University of Mosul.

AL-Zubaidy, Abdulrazzaq Abdullatif Jasem (2004). Effect of irrigation system and soil preparation and softening equipment in some physical properties of the soil and growth of maize crop, PhD thesis, Department of Agricultural Mechanization, Faculty of Agriculture , University of Baghdad.

Aoudah, Mehdi Ibraheem (1990). Principles of Soil Physics (translated), Ministry of Higher Education and Scientific Research. faculty of Agriculture . Albasrah university.

Bukhari, Sheruddin.., Masood Ahamed Bhutto, Jan Muhammed Baloch Mirani. (1988). Performance of selected tillage implements. Agric. Mech. In Asia, Africa and Latin America 19 (4): 9-14.

Daoud, Khaled Mohammed and Zeki Abd Elias (1990). Statistical Methods of Agricultural Research. Directorate of the House of Books for Printing and 
Publishing, University of Mosul, Ministry of Higher Education and Scientific Research.

Ezzat, Abdulsalam Mahmood and Lutfi Husien Mohammed Ali (1979). Agricultural tractors, Baghdad University Press, Baghdad University, Ministry of Higher Education and Scientific Research.

Kashmula, Sinan Bashar Younis (2012), The effect of the type of locally concentrated weapon of the excavator plow and the trapezoid shape in some of the requirements of the physical capacity and properties of the soil, Mastr thesis, Department of Agricultural Mechanization, Faculty of Agriculture and Forestry, University of Mosul.

Naser, Aqeel Joni and Murad Nouri Ramadhan and Sadeq jabbar Muhsen (2016). Study the requirements of drawing and plowing traits for the excavator plow in a silt clay soil, Al - Muthanna Journal for Agricultural Sciences, Vol. (4) Issue (1): 2016.

Plouffe, C.; C. Lague; S. Tessier and M.J. Richard (1999). Moldboard plow Performance in clay soil, Simulation and experiment. Transaction of ASAE(6):1531-1539 .

Rejab, Adel Ahmed Abdullah (2005). Development of the locally produced excavator plow, PhD thesis, Department of Agricultural Mechanization, Faculty of Agriculture and Forestry, University of Mosul.

Saber, Alaa Kamil (2011). Evaluate the performance of the New Holland tractor with the heavy CHISEL plow, Master thesis, Department of Agricultural Machinery, Faculty of Agriculture, University of Baghdad.

Yaya, Abdullah Mohammed (1998). Loading the tractor with both moldboard and disk plow under the conditions of subsistence agriculture, $\mathrm{PhD}$ thesis, Department of Agricultural Mechanization, Faculty of Agriculture and Forestry, University of Mosul. 